\title{
An Analysis of the Earth's Energy Budget
}

\author{
Mulholland Geoscience, Weybridge, Surrey, UK \\ Email address: \\ philip.mulholland@uclmail.net (P. Mulholland) \\ ${ }^{*}$ Corresponding author
}

Stephen Paul Rathbone Wilde, Philip Mulholland*

To cite this article:

Stephen Paul Rathbone Wilde, Philip Mulholland. An Analysis of the Earth's Energy Budget. International Journal of Atmospheric and Oceanic Sciences. Vol. 4, No. 2, 2020, pp. 54-64. doi: 10.11648/j.ijaos.20200402.12

Received: September 13, 2020; Accepted: September 27, 2020; Published: October 7, 2020

\begin{abstract}
In this paper we quantify and attribute by inspection the constituent elements of the power intensity radiant flux transmission for the atmosphere of the Earth, as recorded in the following two published sources; Oklahoma Climatological Survey and Kiehl and Trenberth. The purpose of our analysis is to establish the common elements of the approach used in the formulation of these works, and to conduct an assessment of the two approaches by establishing a common format for their comparison. By applying the standard analysis of a geometric infinite series feed-back loop to an equipartition (half up and half down) diabatic distribution used for the atmospheric radiant flux to all elements of the climate model; our analysis establishes the relative roles of radiant and mass-motion carried energy fluxes that are implicitly used by the authors in their respective analyses. Having established the key controls on energy flux within each model, we then conduct for the canonical model a series of "what-if" scenarios to establish the limits of temperature rise that can be achieved for specific variations in the controls used to calculate the global average temperature. Our analysis establishes that, for the current insolation and Bond albedo, the maximum temperature that can be achieved for a thermally radiant opaque atmosphere is a rise to $29^{\circ} \mathrm{C}$. This global average temperature is achieved by a total blocking of the surface-to-space atmospheric window. In order to raise the global average atmospheric temperature to the expected value of $36^{\circ} \mathrm{C}$ for a putative Cretaceous hothouse world, it is therefore necessary to reduce the planetary Bond albedo. The lack of continental icecaps, and the presence of flooded continental shelves with epeiric seas in a global eustatic high stand sea level, is invoked as an explanation to support the modelling concept of a reduced global Bond albedo during the Cretaceous period. The geological evidence for this supposition is mentioned with reference to published sources.
\end{abstract}

Keywords: Radiation Budget, Climate Model, Atmospheric Window, Bond Albedo, Cretaceous Hothouse World

\section{Introduction}

In this paper we quantify and attribute by inspection the constituent elements of the power intensity radiant flux transmission recorded in two published sources; Oklahoma Climatological Survey [1] and the canonical paper Kiehl and Trenberth [2].

The following two figures, showing the principal features of the Earth's Energy Budget, were published in 1997 by the Oklahoma Climatological Survey (hereafter OK First), and are reproduced here with kind permission [1].

Both of these diagrams when combined provide detailed energy budget information for the Earth's climate; however, their parameters are recorded as percentages of solar illumination at the top of the atmosphere (TOA). Neither diagram published by OK-First records the actual values of solar power intensity, nor is it demonstrated how they can be used to estimate the global average temperature for the surface of the Earth, something that has been shown by us to be achievable using basic climate budget data [3].

A number of assumptions must be made in order to understand how Figures 1 and 2 can be used to estimate the average global temperature of the Earth under an expected solar illumination radiant power intensity of $* 1368 \mathrm{~W} / \mathrm{m}^{2}$, and the albedo of 0.30 used in Figure $1 .{ }^{*} \mathrm{~N}$. B. The standard NASA Earth irradiance is $1361 \mathrm{~W} / \mathrm{m}^{2}$ and the Bond albedo is 0.306 [4]. However, in 1997 the solar irradiance used was $1368 \mathrm{~W} / \mathrm{m}^{2}$, and so this value is used here to give the most appropriate match to this historic paper [2]. 


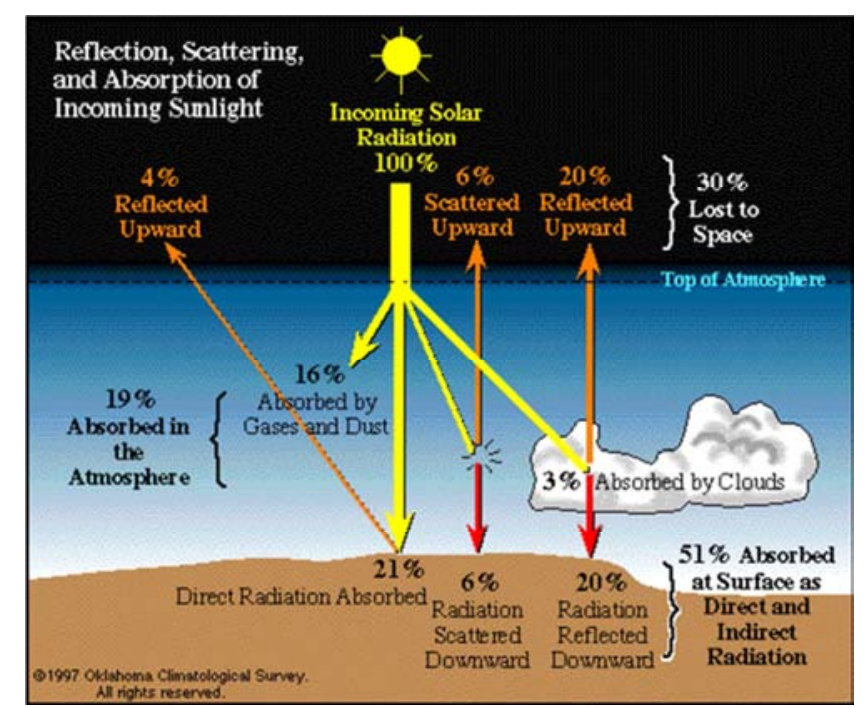

Figure 1. Radiation "Budget" for Incoming Solar Radiation (Oklahoma Climatological Survey) [1].

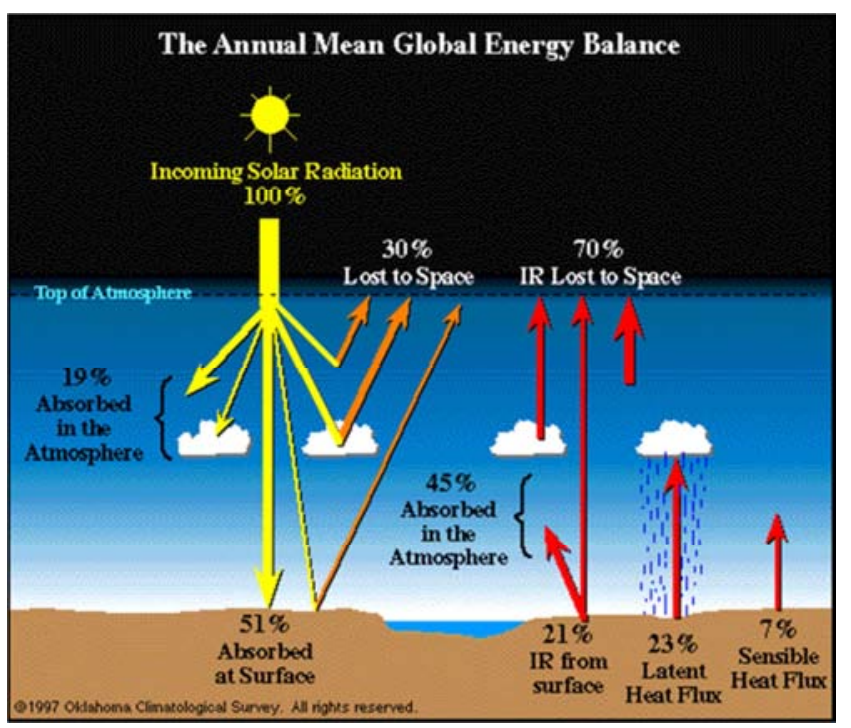

Figure 2. Globally Averaged Energy Budget (Oklahoma Climatological Survey) [1].

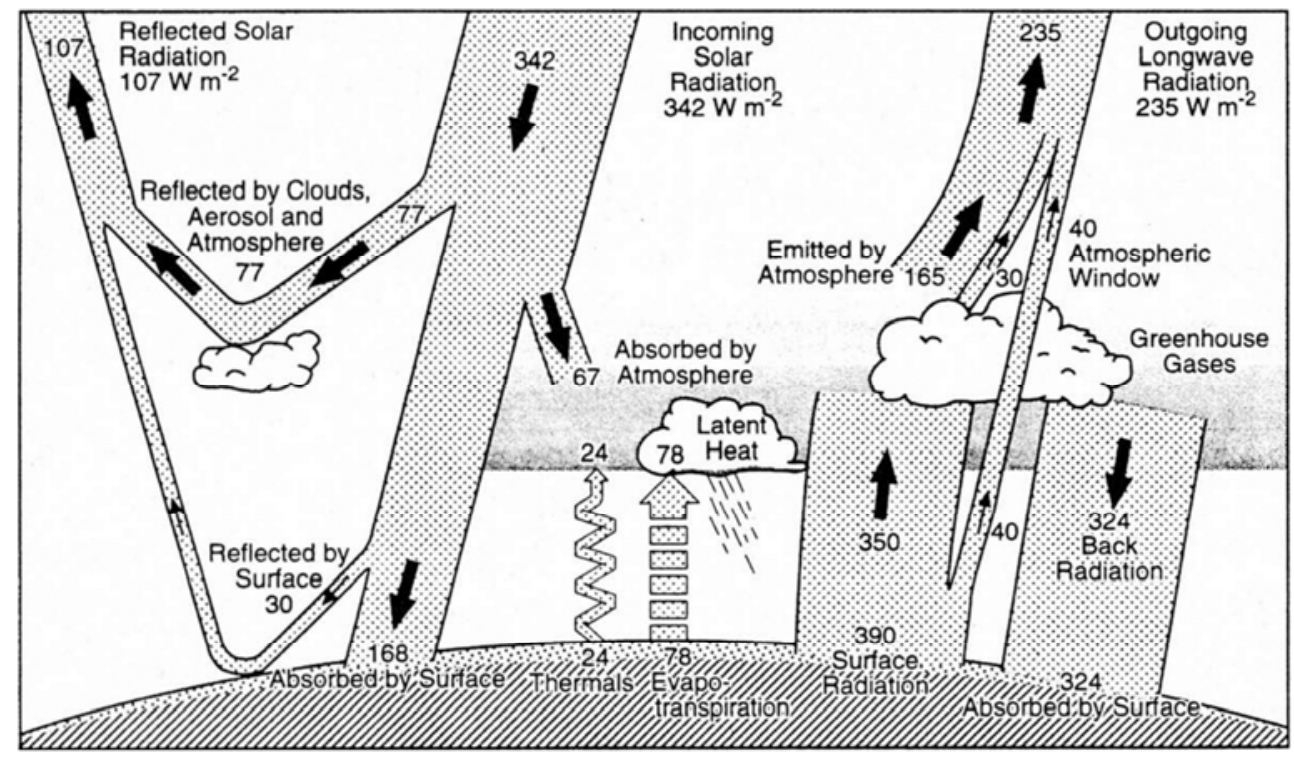

Figure 3. Earth's Annual Global Mean Energy Budget [2] (reproduced with kind permission).

\section{Methodology}

Perhaps the most fundamental issue at the heart of climate modelling is the use of the power intensity illumination divisor of integer 4. This number, derived from spherical geometry, is present in the vacuum planet equation (Equation 1 ), and is used as the foundation principle of climate science.

From Sagan and Chyba [5]:

"The equilibrium temperature $\mathrm{T}_{\mathrm{e}}$ of an airless, rapidly rotating planet is: -

$$
\text { Equation 1: } \mathrm{T}_{\mathrm{e}} \equiv\left[\mathrm{S} \pi \mathrm{R}^{2}(1-\mathrm{A}) / 4 \pi \mathrm{R}^{2} \varepsilon \sigma\right]^{1 / 4}
$$

where $\sigma$ is the Stefan-Boltzmann Constant, $\varepsilon$ the effective surface emissivity, A the wavelength-integrated Bond albedo, $\mathrm{R}$ the planet's radius (in metres), and $\mathrm{S}$ the solar constant (in Watts $/ \mathrm{m}^{2}$ ) at the planet's average distance from the sun."
It is clear by inspection of the canonical energy budget diagram (Figure 3) that the insolation at the Top of the Atmosphere (TOA) is $342 \mathrm{~W} / \mathrm{m}^{2}$. This value is one quarter of the radiant beam power intensity that the globe cuts out from the solar illumination at the Earth's average planetary orbital distance from the Sun [4].

In order to directly compare the analysis of OK First, where the Incoming Solar Radiation (Insolation) is recorded in percentages, with the canonical analysis; we must therefore apply the same logic, and use an insolation diluted by a factor of 4 to convert the recorded percentages in Figures 1 and 2 to power intensity flux in Watts $/ \mathrm{m}^{2}$.

In their percentage analysis of the global energy budget Figure 1 shows that $30 \%$ of the insolation is bypassed via albedo loss, and so only $70 \%$ of the power intensity is available to heat the planet [1]. If we now apply the standard 
divide by 4 spherical geometry rule to the expected (but not yet confirmed) solar irradiance of $1368 \mathrm{~W} / \mathrm{m}^{2}$, then the postalbedo power intensity value will be $235 \mathrm{~W} / \mathrm{m}^{2}$.

However, because the percentages relate to the unfiltered TOA power intensity, it follows that the power intensity values in the OK-First diagrams are percentages of the assumed (but not yet confirmed) pre-albedo value of 342 $\mathrm{W} / \mathrm{m}^{2}$, and so it is this power intensity number that must be used. By this means consistency in both percentages and also power intensity values will be maintained throughout the OK-First diagrams, the elements of which are presented below in Table 1 .

Table 1. Earth's Energy Budget as recorded in OK-First [1].

\begin{tabular}{|c|c|c|c|c|c|}
\hline & $\begin{array}{l}\text { Items recorded as percentages of the intercepted } \\
\text { solar beam }\end{array}$ & Insolation & $\begin{array}{l}\text { Albedo bypass } \\
\text { losses (Figure 1) }\end{array}$ & $\begin{array}{l}\text { Absorbed Insolation } \\
\text { (Figure 1) }\end{array}$ & $\begin{array}{l}\text { Emitted by Surface } \\
\text { (Figure 2) }\end{array}$ \\
\hline \multirow{6}{*}{ Figure 1} & Incoming Solar Radiation & $100 \%$ & & & \\
\hline & Scattered Upward by Air & & $6 \%$ & & \\
\hline & Reflected Upward by Clouds & & $20 \%$ & & \\
\hline & Reflected Upward by Surface & & $4 \%$ & & \\
\hline & Insolation Absorbed by Gases and Dust & & & $16 \%$ & \\
\hline & Insolation Absorbed by Clouds & & & $3 \%$ & \\
\hline \multirow{8}{*}{ Figure 2} & Absorbed at Surface (Direct and Indirect) & & & $51 \%$ & \\
\hline & Surface radiation (part absorbed by air) & & & & $21 \%$ \\
\hline & Surface Sensible Heat Flux & & & & $7 \%$ \\
\hline & Surface Latent Heat Flux & & & & $23 \%$ \\
\hline & Surface IR Radiation (Atmospheric Window Loss) & & & & \\
\hline & Emission by Atmosphere (Implied Value) & & & & \\
\hline & Emission by Clouds (Latent Heat Flux) & & & & \\
\hline & Totals & $100 \%$ & $30 \%$ & $70 \%$ & $51 \%$ \\
\hline
\end{tabular}

Table 1. Continued.

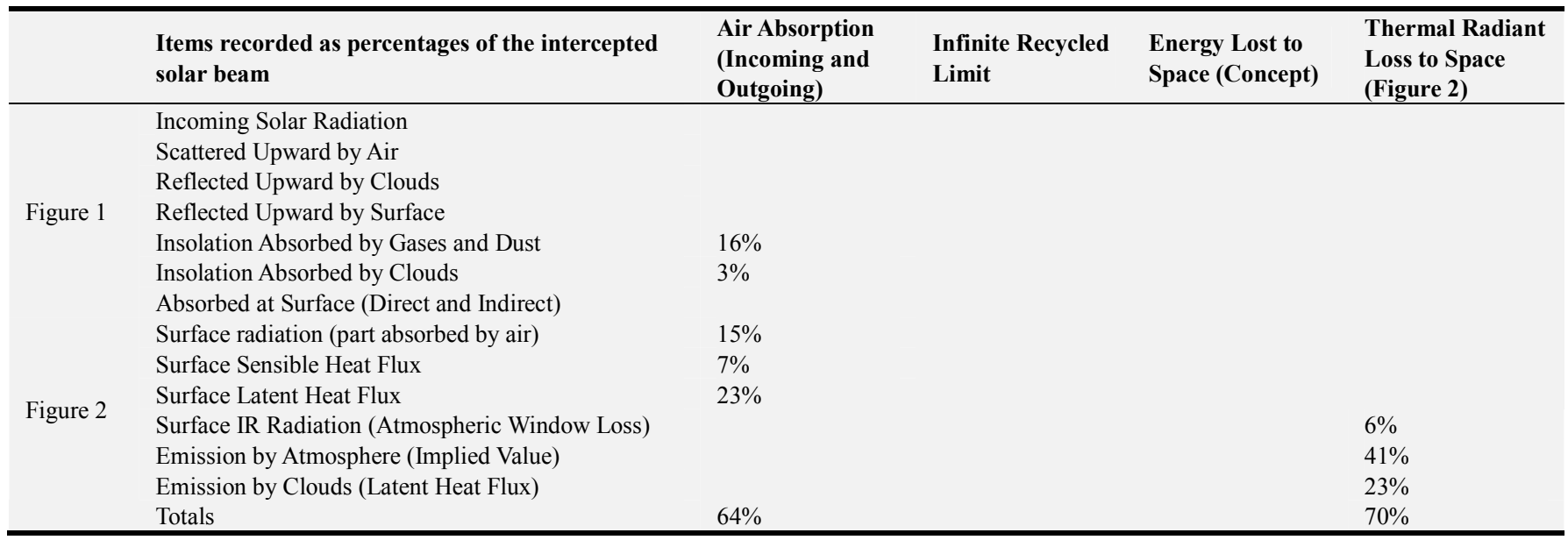

The next assumption we must make is that the standard partition of energy by the atmosphere is being applied. The standard assumption is that for all energy fluxes intercepted by the atmosphere, half of the flux is directed upwards and lost to space, and half of all captured flux is returned to the surface as back radiation and recycled. This concept is shown in figure 4 (reproduced here with kind permission) and is also used in the canonical model $[6,7]$.

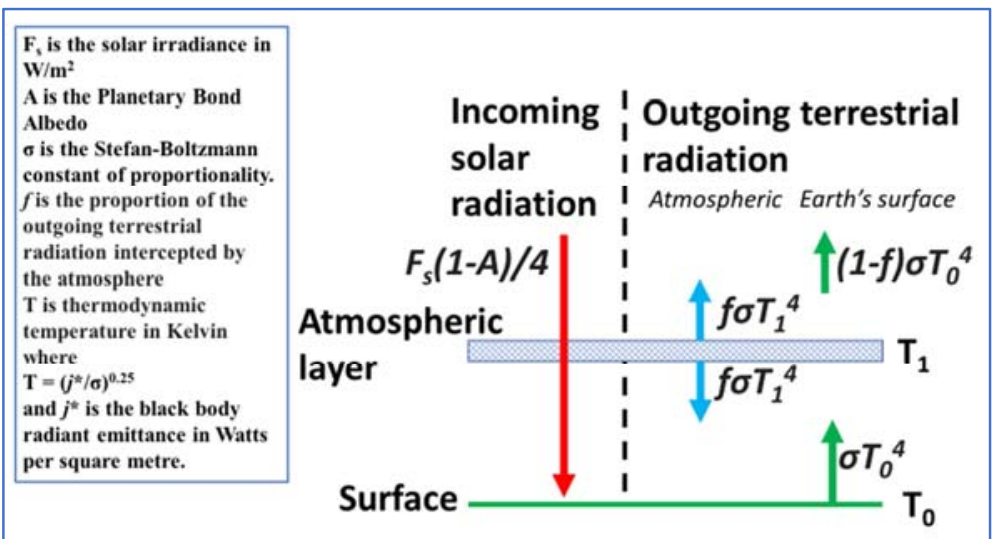

Figure 4. Equipartition of energy flux by the Atmospheric layer [6]. 
Because the intercepted energy flux is being recycled this feed-back loop is an endless sum of halves of halves. It has the mathematical form of a geometric series, and is a sum of the descending fractions in the power sequence $2^{-n}$, where minus $\mathrm{n}$ is a continuous sequence of natural numbers ranging from zero to infinity.

$$
\text { Equation } 2: 1 / 2+1 / 4+1 / 8+1 / 16+1 / 32+\cdots+2^{-n}=1
$$

Equation 2 describes the cumulative effect of the feedback loop (after an infinite series of additions), where for each turn of the cycle, half the ascending energy flux is passed out to space and lost, and the other half is returned back to the ground surface and then re-emitted [7]. It is a feature of this form of an infinite series that the sum of the series is not itself an infinite number, but in this case the limit is the finite natural number 1 . As a direct consequence of applying Equation 2 to the OK-First atmospheric model we must double the energy flux within the atmosphere, because the atmosphere retains and stores an energy flux equal to that of the total intercepted flux. When we apply the logic of the 50\%: 50\% atmospheric energy flux partition to the OK-First analysis, then we are able to create the following table of percentage atmospheric energy recycling (Table 2).

Table 2. Earth's Energy Budget (OK-First) including the elements of the atmospheric recycling process [1].

\begin{tabular}{|c|c|c|c|c|c|}
\hline & $\begin{array}{l}\text { Items recorded as percentages of the intercepted } \\
\text { solar beam }\end{array}$ & Insolation & $\begin{array}{l}\text { Albedo bypass } \\
\text { losses (Figure 1) }\end{array}$ & $\begin{array}{l}\text { Absorbed Insolation } \\
\text { (Figure 1) }\end{array}$ & $\begin{array}{l}\text { Emitted by Surface } \\
\text { (Figure 2) }\end{array}$ \\
\hline \multirow{7}{*}{ Figure 1} & Incoming Solar Radiation & $100 \%$ & & & \\
\hline & Scattered Upward by Air & & $6 \%$ & & \\
\hline & Reflected Upward by Clouds & & $20 \%$ & & \\
\hline & Reflected Upward by Surface & & $4 \%$ & & \\
\hline & Insolation Absorbed by Gases and Dust & & & $16 \%$ & \\
\hline & Insolation Absorbed by Clouds & & & $3 \%$ & \\
\hline & Absorbed at Surface (Direct and Indirect) & & & $51 \%$ & \\
\hline \multirow{7}{*}{ Figure 2} & Surface radiation (part absorbed by air) & & & & $21 \%$ \\
\hline & Surface Sensible Heat Flux & & & & $7 \%$ \\
\hline & Surface Latent Heat Flux & & & & $23 \%$ \\
\hline & Surface IR Radiation (Atmospheric Window Loss) & & & & \\
\hline & Emission by Atmosphere (Implied Value) & & & & \\
\hline & Emission by Clouds (Latent Heat Flux) & & & & \\
\hline & Totals & $100 \%$ & $30 \%$ & $70 \%$ & $51 \%$ \\
\hline
\end{tabular}

Table 2. Continued.

\begin{tabular}{|c|c|c|c|c|c|}
\hline & $\begin{array}{l}\text { Items recorded as percentages of the intercepted } \\
\text { solar beam }\end{array}$ & $\begin{array}{l}\text { Air Absorption } \\
\text { (Incoming and } \\
\text { Outgoing) }\end{array}$ & $\begin{array}{l}\text { Infinite Recycled } \\
\text { Limit }\end{array}$ & $\begin{array}{l}\text { Energy Lost to } \\
\text { Space (Concept) }\end{array}$ & $\begin{array}{l}\text { Thermal Radiant } \\
\text { Loss to Space } \\
\text { (Figure 2) }\end{array}$ \\
\hline \multirow{6}{*}{ Figure 1} & Incoming Solar Radiation & & & & \\
\hline & Scattered Upward by Air & & & & \\
\hline & Reflected Upward by Clouds & & & & \\
\hline & Reflected Upward by Surface & & & & \\
\hline & Insolation Absorbed by Gases and Dust & $16 \%$ & $16 \%$ & $16 \%$ & \\
\hline & Absorbed at Surface (Direct and Indirect) & & & & \\
\hline \multirow{6}{*}{ Figure 2} & Surface radiation (part absorbed by air) & $15 \%$ & $15 \%$ & $15 \%$ & \\
\hline & Surface Sensible Heat Flux & $7 \%$ & $7 \%$ & $7 \%$ & \\
\hline & Surface Latent Heat Flux & $23 \%$ & $23 \%$ & $23 \%$ & \\
\hline & Surface IR Radiation (Atmospheric Window Loss) & & & $6 \%$ & $6 \%$ \\
\hline & Emission by Atmosphere (Implied Value) & & & & $41 \%$ \\
\hline & Emission by Clouds (Latent Heat Flux) & & & & $23 \%$ \\
\hline
\end{tabular}

Table 2 demonstrates that the power intensity experienced by the atmosphere is composed of two components, the $64 \%$ that is absorbed by the air, and the $64 \%$ that derives from the infinite recycling process. To this $128 \%$ capture of the incoming solar beam (pre-albedo measure) there is in addition the power intensity flux emitted by the surface, and directly attributable to the high frequency insolation that impinges on it, which adds another $51 \%$ to the planetary energy budget. This means that the total power intensity flux that drives the Earth's climate is $179 \%$ of the pre-albedo TOA insolation according to our assessment of the OK-First diagram.

In addition, for Table 2 we propose that the column for the energy lost to space in Figure 2 can be replaced with a new concept column that lists the constituent elements of the recycling process. These elements are allocated in a way that preserves their relative roles and sums to the expected exhaust-to-space flux of $70 \%$.

For the next stage of the analysis we now apply an identical process of deconstruction to the accepted diagram of Kiehl and Trenberth, with its recorded power intensity values (Figure 3), and compare this with the atmospheric 
absorption elements as listed in Figures 1 and 2 [1].

Table 3. Earth's Annual Global Mean Energy Budget including the elements of the atmospheric recycling process. [2]

\begin{tabular}{|c|c|c|c|c|}
\hline Items recorded in W/m ${ }^{2}$ & Insolation & Albedo bypass losses & Absorbed Insolation & Emitted by surface (Losses) \\
\hline Incoming Solar Radiation & 342.00 & & & \\
\hline Reflected by Clouds, Aerosol and Atmosphere & & 77.00 & & \\
\hline Reflected by Surface & & 30.00 & & \\
\hline Insolation Absorbed by Atmosphere & & & 67.00 & \\
\hline Insolation Absorbed by Surface & & & 168.00 & \\
\hline Surface Radiation (part absorbed by air) & & & & 26.00 \\
\hline Surface Thermals & & & & 24.00 \\
\hline Surface Evaporation & & & & 78.00 \\
\hline Surface IR Radiation (Atmospheric Window Loss) & & & & 40.00 \\
\hline \multicolumn{5}{|l|}{ Emission by Atmosphere } \\
\hline \multicolumn{5}{|l|}{ Emission by Clouds } \\
\hline Totals & 342.00 & 107.00 & 235.00 & 168.00 \\
\hline
\end{tabular}

Table 3. Continued.

\begin{tabular}{|c|c|c|c|c|}
\hline Items recorded in $\mathrm{W} / \mathrm{m}^{2}$ & $\begin{array}{l}\text { Air Absorption } \\
\text { (Incoming and Outgoing) }\end{array}$ & $\begin{array}{l}\text { Infinite Recycled } \\
\text { Limit }\end{array}$ & $\begin{array}{l}\text { Energy Lost to } \\
\text { Space (Concept) } \\
\end{array}$ & $\begin{array}{l}\text { Energy Lost to } \\
\text { Space (Diagram) }\end{array}$ \\
\hline \multicolumn{5}{|l|}{ Incoming Solar Radiation } \\
\hline \multicolumn{5}{|l|}{ Reflected by Clouds, Aerosol and Atmosphere } \\
\hline \multicolumn{5}{|l|}{ Reflected by Surface } \\
\hline Insolation Absorbed by Atmosphere & 67.00 & 67.00 & 67.00 & \\
\hline \multicolumn{5}{|l|}{ Insolation Absorbed by Surface } \\
\hline Surface Radiation (part absorbed by air) & 26.00 & 26.00 & 26.00 & \\
\hline Surface Thermals & 24.00 & 24.00 & 24.00 & \\
\hline Surface Evaporation & 78.00 & 78.00 & 78.00 & \\
\hline Surface IR Radiation (Atmospheric Window Loss) & & & 40.00 & 40.00 \\
\hline Emission by Atmosphere & & & & 165.00 \\
\hline Emission by Clouds & & & & 30.00 \\
\hline Totals & 195.00 & 195.00 & 235.00 & 235.00 \\
\hline
\end{tabular}

Table 3 demonstrates that the total power intensity flux absorbed by the atmosphere in the Kiehl and Trenberth diagram is $195 \mathrm{~W} / \mathrm{m}^{2}$, and that this power intensity is then doubled to $390 \mathrm{~W} / \mathrm{m}^{2}$ by the process of atmospheric recycling, which includes recycling of both the thermals and also evaporation energy fluxes.

As was shown in Table 2 we propose that the column for the energy lost to space in Figure 3 can be replaced with a new concept column that lists the constituent elements of the recycling process. As before, these elements are allocated in a way that preserves their relative roles and sums to the expected exhaust-to-space flux of $235 \mathrm{~W} / \mathrm{m}^{2}$ [2].

Table 4 below demonstrates that the total energy budget for the Earth is $558 \mathrm{~W} / \mathrm{m}^{2}$. The constituent elements of this sum are the $168 \mathrm{~W} / \mathrm{m}^{2}$ of surface intercepted insolation; to this must be added the intercepted and recycled atmospheric flux of 390 $\mathrm{W} / \mathrm{m}^{2}$ (that contains the direct atmospheric solar interception of $67 \mathrm{~W} / \mathrm{m}^{2}$ ) to give a planetary energy budget of $558 \mathrm{~W} / \mathrm{m}^{2}$.

By using the standard Stefan-Boltzmann relationship (Equation 3) this captured power intensity can be converted to a thermodynamic temperature

$$
\text { Equation 3: } \mathrm{T}=(j * / \sigma)^{0.25}
$$

Where $j^{*}$ is the black body radiant emittance in Watts per square metre and $\sigma$ is the Stefan-Boltzmann Constant. Then the total planetary energy budget of $558 \mathrm{~W} / \mathrm{m}^{2}$ converts to a thermodynamic temperature for the Earth's surface of 315 Kelvin $\left(42^{\circ}\right.$ Celsius) (Table 4$)$.

However, in the energy budget analysis the surface fluxes of:

1. Net Surface Longwave Radiation $\left(390-324=66 \mathrm{~W} / \mathrm{m}^{2}\right)$

2. Ascending Atmospheric Thermals $\left(24 \mathrm{~W} / \mathrm{m}^{2}\right)$

3 . Evaporation - both open water surfaces and living plants $\left(78 \mathrm{Wm}^{2}\right)$

are all losses that create surface cooling, and so combine to reduce the expected Surface Radiation flux to $390 \mathrm{~W} / \mathrm{m} 2$ after these total losses are applied.

Using Equation 3 to convert irradiance power intensity to thermodynamic temperature, the average temperature of the Earth's atmosphere for a net atmospheric power intensity flux of $390 \mathrm{~W} / \mathrm{m}^{2}$ is shown to be 288 Kelvin $\left(15^{\circ}\right.$ Celsius) (Table 4).

Table 4. Key Energy Budget Metrics [2].

\begin{tabular}{llllll}
\hline & \multicolumn{2}{l}{ From Figure 3: Kiehl and Trenberth [2] } & & \\
\cline { 2 - 6 } Key Energy Budget Metrics & $\begin{array}{l}\text { Power Intensity \% of } \\
\text { Unfiltered Sunlight }\end{array}$ & $\begin{array}{l}\text { Power Intensity } \\
\mathbf{W} / \mathbf{m}^{\mathbf{2}}\end{array}$ & $\begin{array}{l}\text { System Gain by } \\
\text { Component w.r.t. } \\
\mathbf{2 3 5} \mathbf{~ W / \mathbf { m } ^ { 2 }}\end{array}$ & $\begin{array}{l}\text { Temperature } \\
\text { Kelvin }\end{array}$ & $\begin{array}{l}\text { Temperature } \\
\text { Celsius }\end{array}$ \\
\hline Raw Planet Filtered Insolation & $68.71 \%$ & 235.00 & 254 & -19 \\
Raw Surface Absorbed Insolation & $49.12 \%$ & 168.00 & 233 & -40 \\
\hline
\end{tabular}




\begin{tabular}{|c|c|c|c|c|c|}
\hline \multirow[b]{2}{*}{ Key Energy Budget Metrics } & \multicolumn{5}{|c|}{ From Figure 3: Kiehl and Trenberth [2] } \\
\hline & $\begin{array}{l}\text { Power Intensity \% of } \\
\text { Unfiltered Sunlight }\end{array}$ & $\begin{array}{l}\text { Power Intensity } \\
\mathrm{W} / \mathrm{m}^{2}\end{array}$ & $\begin{array}{l}\text { System Gain by } \\
\text { Component w.r.t. } \\
235 \mathrm{~W} / \mathrm{m}^{2}\end{array}$ & $\begin{array}{l}\text { Temperature } \\
\text { Kelvin }\end{array}$ & $\begin{array}{l}\text { Temperature } \\
\text { Celsius }\end{array}$ \\
\hline Air Absorption (Incoming and Outgoing) & $57.02 \%$ & 195.00 & & & \\
\hline Recycled Atmospheric Energy & $57.02 \%$ & 195.00 & & & \\
\hline Total Enhanced Surface Power Intensity & $163.16 \%$ & 558.00 & 2.37 & 315 & 42 \\
\hline 1. Direct Solar Radiation (Loss) & $7.60 \%$ & 26.00 & & & \\
\hline 2. Surface Thermals (Loss) & $7.02 \%$ & 24.00 & & & \\
\hline 3. Surface Evaporation (Loss) & $22.81 \%$ & 78.00 & & & \\
\hline 4. Atmospheric Window to Space (Loss) & $11.70 \%$ & 40.00 & & & \\
\hline Remaining Surface Radiant Power Intensity & $114.04 \%$ & 390.00 & 1.66 & 288 & 15 \\
\hline Top of Atmosphere Radiant Exhaust & $68.71 \%$ & 235.00 & 1.00 & 254 & -19 \\
\hline \multirow[b]{2}{*}{ 3. Results } & & \multicolumn{4}{|c|}{ Earth Insolation Metrics [2] } \\
\hline & & \multicolumn{2}{|c|}{$\begin{array}{l}\text { Earth Bond Albedo } \\
\text { Dimmed Intercepted Beam W/m² }\end{array}$} & & $\begin{array}{l}0.300 \\
239.40\end{array}$ \\
\hline \multicolumn{2}{|c|}{$\begin{array}{l}\text { Having established that the canonical model incorporates a } \\
\text { process of equipartition flux recycling in the atmosphere, and } \\
\text { that this recycling applies to both the radiant energy flux and } \\
\text { also to the air and water mass motion fluxes, we now apply } \\
\text { the same process of analysis to the OK First diagrams. }\end{array}$} & \multirow{4}{*}{\multicolumn{4}{|c|}{$\begin{array}{l}\text { In order to maintain parity between the two papers we } \\
\text { apply the same TOA input flux of } 342 \mathrm{~W} / \mathrm{m}^{2} \text { (Table 5) used } \\
\text { in Figure } 3 \text { and apply this value to the table of percentages } \\
\text { created from the OK-First diagrams and displayed in Table } 2 \text {. } \\
\text { This insolation power intensity flux of } 342 \mathrm{~W} / \mathrm{m}^{2} \text {, when } \\
\text { combined with the published percentages of OK-First can be } \\
\text { used to create a table of power intensity values (Table 6) and } \\
\text { also to create their associated thermodynamic temperatures } \\
\text { (Table 7). }\end{array}$}} \\
\hline Table 5. Suggested Earth Insolation Met & K-First diagram. & & & & \\
\hline \multicolumn{2}{|l|}{ Earth Insolation Metrics [2] } & & & & \\
\hline $\begin{array}{l}\text { Earth's Solar Irradiance } \mathrm{W} / \mathrm{m}^{2} \\
\text { Divide by } 4 \text { Geometry Rule W/m }\end{array}$ & $\begin{array}{l}1368.00 \\
342.00\end{array}$ & & & & \\
\hline
\end{tabular}

Table 6. Earth's Energy Budget (inferred from OK-First [1]). Items recorded in $\mathrm{W} / \mathrm{m}^{2}$ relative to the intercepted solar beam.

\begin{tabular}{|c|c|c|c|c|c|}
\hline & $\begin{array}{l}\text { Adapted from Figures } 1 \text { and 2: OK-First [1] Items } \\
\text { recorded in } \mathrm{W} / \mathrm{m}^{2}\end{array}$ & Insolation & $\begin{array}{l}\text { Albedo bypass } \\
\text { losses (Figure 1) }\end{array}$ & $\begin{array}{l}\text { Absorbed Insolation } \\
\text { (Figure 1) }\end{array}$ & $\begin{array}{l}\text { Emitted by Surface } \\
\text { (Figure 2) }\end{array}$ \\
\hline \multirow{6}{*}{ Figure 1} & Incoming Solar Radiation & 342.00 & & & \\
\hline & Scattered Upward by Air & & 20.52 & & \\
\hline & Reflected Upward by Clouds & & 68.40 & & \\
\hline & Reflected Upward by Surface & & 13.68 & & \\
\hline & Insolation Absorbed by Gases and Dust & & & 54.72 & \\
\hline & Insolation Absorbed by Clouds & & & 10.26 & \\
\hline \multirow{8}{*}{ Figure 2} & Absorbed at Surface (Direct and Indirect) & & & 174.42 & \\
\hline & Surface radiation (part absorbed by air) & & & & 71.82 \\
\hline & Surface Sensible Heat Flux & & & & 23.94 \\
\hline & Surface Latent Heat Flux & & & & 78.66 \\
\hline & Surface IR Radiation (Atmospheric Window Loss) & & & & \\
\hline & Emission by Atmosphere (Implied Value) & & & & \\
\hline & Emission by Clouds (Latent Heat Flux) & & & & \\
\hline & Totals & 342.00 & 102.60 & 239.40 & 174.42 \\
\hline
\end{tabular}

Table 6. Continued.

\begin{tabular}{|c|c|c|c|c|c|}
\hline & $\begin{array}{l}\text { Adapted from Figures } 1 \text { and 2: OK-First [1] Items } \\
\text { recorded in } \mathrm{W} / \mathrm{m}^{2}\end{array}$ & $\begin{array}{l}\text { Air Absorption } \\
\text { (Incoming \& } \\
\text { Outgoing) }\end{array}$ & $\begin{array}{l}\text { Infinite Recycled } \\
\text { Limit }\end{array}$ & $\begin{array}{l}\text { Energy Lost to } \\
\text { Space (Concept) }\end{array}$ & $\begin{array}{l}\text { IR Lost to Space } \\
\text { (Figure 2) }\end{array}$ \\
\hline \multirow{7}{*}{ Figure 1} & Incoming Solar Radiation & & & & \\
\hline & Scattered Upward by Air & & & & \\
\hline & Reflected Upward by Clouds & & & & \\
\hline & Reflected Upward by Surface & & & & \\
\hline & Insolation Absorbed by Gases and Dust & 54.72 & 54.72 & 54.72 & \\
\hline & Insolation Absorbed by Clouds & 10.26 & 10.26 & 10.26 & \\
\hline & Absorbed at Surface (Direct and Indirect) & & & & \\
\hline \multirow{7}{*}{ Figure 2} & Surface radiation (part absorbed by air) & 51.30 & 51.30 & 51.30 & \\
\hline & Surface Sensible Heat Flux & 23.94 & 23.94 & 23.94 & \\
\hline & Surface Latent Heat Flux & 78.66 & 78.66 & 78.66 & \\
\hline & Surface IR Radiation (Atmospheric Window Loss) & & & 20.52 & 20.52 \\
\hline & Emission by Atmosphere (Implied Value) & & & & 140.22 \\
\hline & Emission by Clouds (Latent Heat Flux) & & & & 78.66 \\
\hline & Totals & 218.88 & 218.88 & 239.40 & 239.40 \\
\hline
\end{tabular}


Table 7. Key Energy Budget Metrics (inferred from OK-First [1]).

\begin{tabular}{|c|c|c|c|c|}
\hline \multirow{2}{*}{ Key Energy Budget Metrics } & \multicolumn{4}{|c|}{ From Figures 1 and 2: OK-First [1] } \\
\hline & Power Intensity \% & Power Intensity $\mathrm{W} / \mathrm{m}^{2}$ & Temperature Kelvin & Temperature Celsius \\
\hline Raw Planet Filtered Insolation & $70 \%$ & 239.40 & 255 & -18 \\
\hline Raw Surface Absorbed Insolation & $51 \%$ & 174.42 & 236 & -37 \\
\hline Air Absorption (Incoming and Outgoing) & $64 \%$ & 218.88 & & \\
\hline Recycled Atmospheric Energy & $64 \%$ & 218.88 & & \\
\hline Enhanced Surface Power Intensity & $179 \%$ & 612.18 & 322 & 49 \\
\hline 1. Surface Longwave Radiation (Loss) & $21 \%$ & 71.82 & & \\
\hline 2. Surface Sensible Heat (Loss) & $7 \%$ & 23.94 & & \\
\hline 3. Surface Evaporation (Loss) & $23 \%$ & 78.66 & & \\
\hline Surface Radiant Power Intensity & $128 \%$ & 437.76 & 296 & 23 \\
\hline Top of Atmosphere Radiant Exhaust & $70 \%$ & 239.40 & 255 & -18 \\
\hline
\end{tabular}

The global average surface temperature of $23^{\circ} \mathrm{C}$ calculated using the OK-First data is higher than that calculated by Kiehl and Trenberth $[1,2]$. This temperature difference arises from a number of possible causes:

1. The OK-First model is using a lower Bond albedo.

2. The solar irradiance used by OK-First for the calculation of percentages is unknown but assumed to be the same number as that used by Kiehl and Trenberth

3. The balance of energy partition fluxes within the OKFirst model is different from the canonical model, and this is the most likely cause of the bias towards the calculated higher global average temperature.

\section{Discussion}

Kiehl and Trenberth and OK-First both use identical concepts in the formation of their global energy budget diagrams. However, both originators present their results in ways that do not clearly demonstrate the commonality or the rigor of the concepts they used.

To clarify this point, we have created an alternative diagram based on Table 4 and using the data of the canonical model in which the role of the atmosphere as an energy recycling reservoir is demonstrated. The key components of figure 5 are that for each flux captured by the atmosphere, an additional and equal quantity is retained by the process of infinite geometric recycling outlined by equation 2 . It is by this means that the $390 \mathrm{~W} / \mathrm{m}^{2}$ of Back Radiation of the canonical model is created and stored in the atmospheric reservoir (Figure 5).

Both sources have failed to illustrate the implicit role of atmospheric mass movement in the process of energy recycling that also heats the surface of our planet. In the presence of a gravity field that binds the atmosphere to the surface of a planet, what goes up must come down.

The distribution of energy fluxes in Table 3 show that for the total atmospheric energy budget of $558 \mathrm{~W} / \mathrm{m}^{2}$ (Table 4), $63.44 \%\left(354 \mathrm{~W} / \mathrm{m}^{2}\right)$ is transmitted by radiation fluxes, and $36.56 \%\left(204 \mathrm{~W} / \mathrm{m}^{2}\right)$ is carried by recycled mass motion (Surface Thermals and Evaporation, Figure 5) for the canonical model (Table 8).

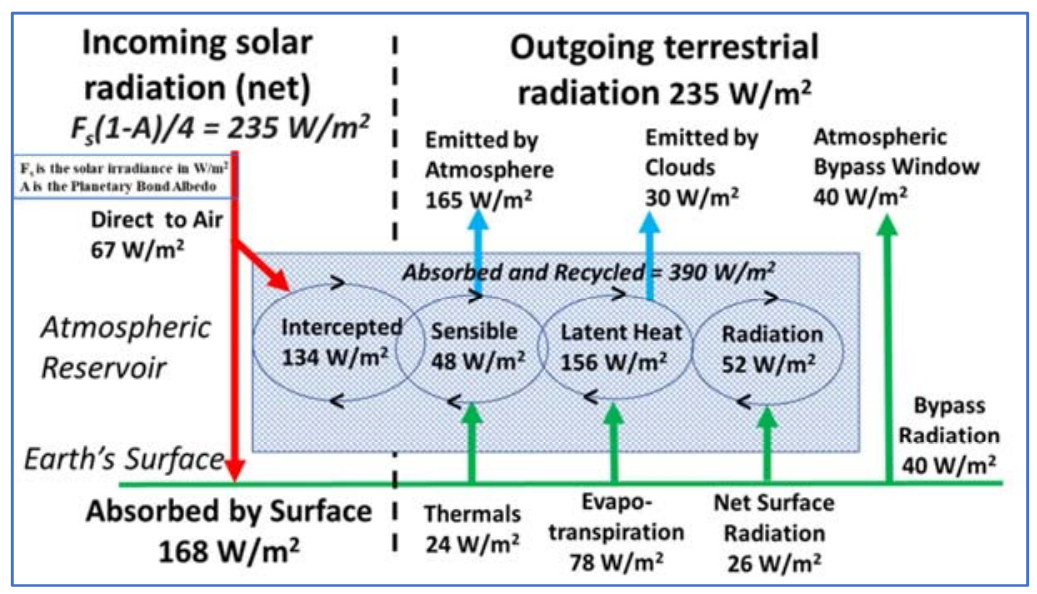

Figure 5. The Atmospheric Reservoir Energy Recycling Process

Table 8. Relative importance of atmospheric flux transmission mechanisms [2].

\begin{tabular}{lll}
\hline Flux type & Flux Intensity $\left(\mathbf{W} / \mathbf{m}^{2}\right)$ & Percentage Load \\
\hline Radiant Flux & 354 & $63.44 \%$ \\
Mass and Latent Flux & 204 & $36.56 \%$ \\
Total Budget & 558 & $100.00 \%$ \\
\hline
\end{tabular}

So clearly mass motion is an important energy carrying process within the Earth's atmosphere.

It is critical to understand at this point that because our energy budget is formulated in terms of power intensity, if the proportion of flux carried by mass motion increases due 
to an increase in moist convection overturning, then the proportion of energy transmitted by radiant processes must decrease (or vice versa). A given energy flux cannot do two things at once, a balance is always maintained between these two distinct processes if the Bond albedo remains constant (Figure 5).

In addition, we find that because the energy budgets of OK-First and also Kiehl and Trenberth are clearly built on the equipartition of energy by the atmosphere (half up and half down), then there are only three ways that the internal energy budget of the Earth's atmosphere can be increased:
1. By closing the longwave surface-to-space atmospheric window, which causes more energy to be recycled within the atmosphere.

2. By decreasing the planetary Bond albedo, which allows more solar energy to enter the climate system.

3. By increasing the planetary atmospheric mass, which causes the surface datum boiling point of water to increase.

Issue \#1 relates directly to concerns that carbon dioxide emissions increase the opacity of our semi-transparent atmosphere, and will close the atmospheric window (Figure 6).

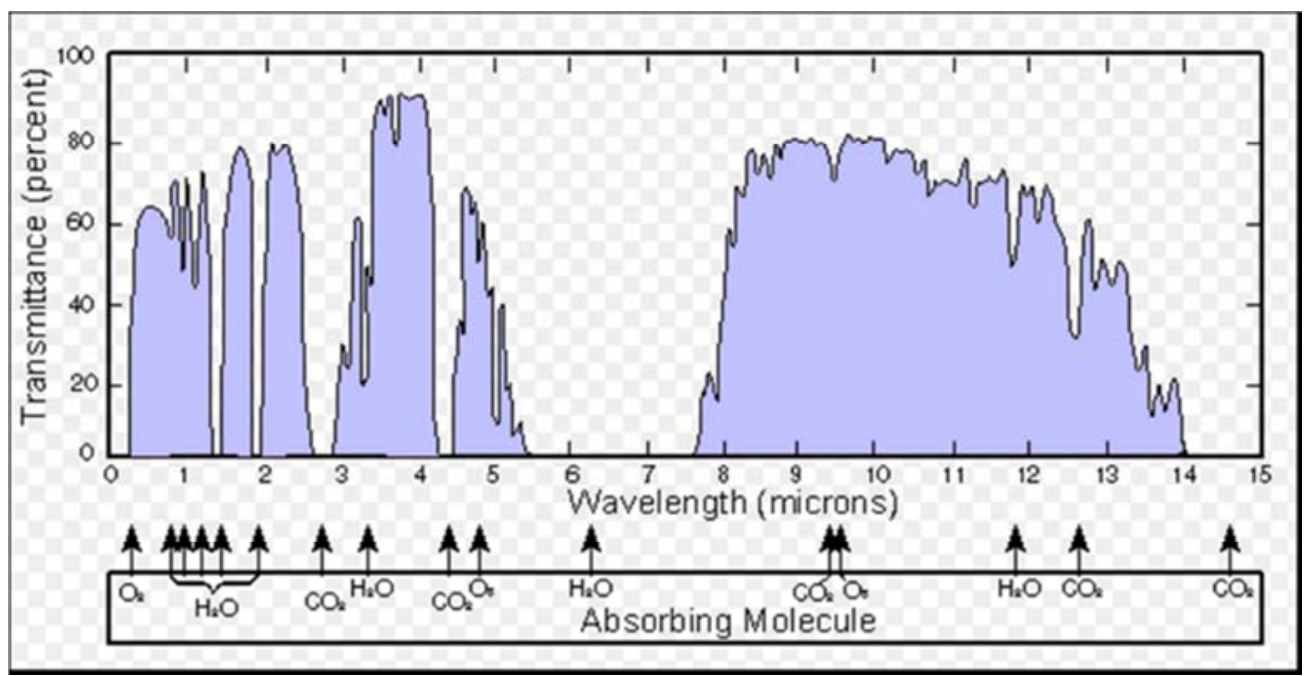

Figure 6 Earth's infrared atmospheric window. (Public Open Licence).

Table 9. The impact of blocking the atmospheric window on the Earth's Global Energy Budget.

\begin{tabular}{|c|c|c|c|c|}
\hline $\begin{array}{l}\text { Adapted from Figure 3: Kiehl and Trenberth [2] } \\
\text { Items recorded in W/m }\end{array}$ & Insolation & $\begin{array}{l}\text { Albedo bypass } \\
\text { losses }\end{array}$ & $\begin{array}{l}\text { Absorbed } \\
\text { Insolation }\end{array}$ & $\begin{array}{l}\text { Emitted by surface } \\
\text { (Losses) }\end{array}$ \\
\hline Incoming Radiation & 342.00 & & & \\
\hline Backscattered by air \& Reflected by clouds & & 77.00 & & \\
\hline Reflected by surface & & 30.00 & & \\
\hline Insolation Absorbed by vapour, dust, Ozone, clouds & & & 67.00 & \\
\hline Insolation Absorbed by surface & & & 168.00 & \\
\hline Surface Radiation (Fully absorbed by air) & & & & 66.00 \\
\hline Surface Evaporation & & & & 78.00 \\
\hline \multicolumn{5}{|l|}{ Surface IR Radiation (Atmospheric Window Loss) } \\
\hline \multicolumn{5}{|l|}{ Emission by Atmosphere } \\
\hline \multicolumn{5}{|l|}{ Emission by Clouds } \\
\hline Totals & 342.00 & 107.00 & 235.00 & 168.00 \\
\hline
\end{tabular}

Table 9. Continued.

\begin{tabular}{lll}
\hline $\begin{array}{l}\text { Adapted from Figure 3: Kiehl and Trenberth [2] } \\
\text { Items recorded in W/m }\end{array}$ & $\begin{array}{l}\text { Air Absorption (Incoming } \\
\text { \& Outgoing) }\end{array}$ & $\begin{array}{l}\text { Energy Lost to Space } \\
\text { (Concept) }\end{array}$ \\
\hline $\begin{array}{l}\text { Incoming Radiation } \\
\text { Backscattered by air \& Reflected by clouds }\end{array}$ & \\
$\begin{array}{l}\text { Reflected by surface } \\
\text { Insolation Absorbed by vapour, dust, Ozone, clouds }\end{array}$ & 67.00 & 67.00 \\
Insolation Absorbed by surface & & \\
Surface Radiation (Fully absorbed by air) & 66.00 & 66.00 \\
Surface Thermals & 24.00 & 24.00 \\
Surface Evaporation & 78.00 & 78.00 \\
Surface IR Radiation (Atmospheric Window Loss) & & \\
Emission by Atmosphere & & 235.00 \\
Emission by Clouds & & \\
Totals & 235.00 & 757.00 \\
\hline
\end{tabular}


We can test the effects of closing this window on global average temperature by using Table 3, and diverting the 40 $\mathrm{W} / \mathrm{m}^{2}$ direct-to-space radiant emission into atmospheric capture and heating, and thereby increase this element of the budget to $66 \mathrm{~W} / \mathrm{m}^{2}$ (Table 9).

The impact of closing the Earth's long-wave emission atmospheric window is to raise the global average temperature from $15^{\circ} \mathrm{C}$ to $29^{\circ} \mathrm{C}$ (Table 10). This $14^{\circ} \mathrm{C}$ increase is the maximum possible temperature increase that the Earth can experience by internal energy recycling for a constant Bond albedo of 0.306 .

Table 10. The Thermal Effects of Blocking the Earth's Atmospheric Window.

\begin{tabular}{lllll}
\hline \multirow{2}{*}{ Key Energy Budget Metrics } & \multicolumn{2}{c}{ Adapted from Figure 3: Kiehl and Trenberth [2] } & & Temperature Celsius \\
\cline { 2 - 5 } & Power Intensity \% & Power Intensity W/m & Temperature Kelvin & -19 \\
\hline Raw Planet Filtered Insolation & $68.71 \%$ & 235.00 & 254 & -40 \\
Raw Surface Absorbed Insolation & $49.12 \%$ & 168.00 & 233 & \\
Air Absorption (Incoming \& Outgoing) & $68.71 \%$ & 235.00 & & 53 \\
Recycled Atmospheric Energy & $68.71 \%$ & 235.00 & 326 & \\
Enhanced Surface Power Intensity & $186.55 \%$ & 638.00 & & \\
1. Surface Longwave Radiation (Loss) & $19.30 \%$ & 66.00 & & \\
2. Surface Thermals (Loss) & $7.02 \%$ & 24.00 & 302 & -19 \\
3. Surface Evaporation (Loss) & $22.81 \%$ & 78.00 & 254 & \\
Surface Radiant Power Intensity & $137.43 \%$ & 470.00 & & \\
Top of Atmosphere Radiant Exhaust & $68.71 \%$ & 235.00 & & \\
\hline
\end{tabular}

In order to further raise the Earth's average global temperature above $29^{\circ} \mathrm{C}$ to form a Cretaceous hothouse world it is necessary to either increase the atmospheric mass, (thereby raising atmospheric pressure and also the boiling point of water), or to reduce the planetary brightness by lowering the Earth's Bond albedo.

Assuming a total blocking of the atmospheric thermal radiant window, and also assuming no increase in atmospheric mass, then it is possible to achieve a Cretaceous global average temperature of $36^{\circ} \mathrm{C}$ with a planetary Bond albedo of 0.244 (Table 11).

This reduction in planetary brightness can be achieved by having a Cretaceous world with no land surface icecaps, and also an increased continental surface inundation associated with a high global sea level [8]. Flooding the land surfaces of the low-lying continents will increase the percentage surface area of the Earth that is covered by ocean water. This flooding will allow the seas to capture and retain more high frequency insolation, and so create a low albedo hothouse world (Table 12). The geological evidence for the lack of a north polar icecap in the Late Cretaceous was presented by Lena Golovneva in a study based on taxonomic and ecological analysis of fossil floras, leaf physiognomy and the distribution of dinosaurian faunas in the high paleo-arctic [9].

Table 11. Cretaceous World Insolation Metrics.

\begin{tabular}{ll}
\hline Illustrative Cretaceous Earth Insolation Metrics & \\
\hline Earth's Solar Irradiance W/m & \\
Divide by 4 Geometry Rule W/m & 1368.00 \\
Cretaceous Earth Bond Albedo & 342.00 \\
Dimmed Intercepted Beam W/m & 0.244 \\
\hline
\end{tabular}

Table 12. Putative Cretaceous Hothouse World.

\begin{tabular}{|c|c|c|c|c|c|c|c|}
\hline $\begin{array}{l}\text { Adapted from Figure 3: Kiehl and Trenberth [2] Items } \\
\text { recorded in } \mathrm{W} / \mathrm{m}^{2}\end{array}$ & Insolation & $\begin{array}{l}\text { Albedo } \\
\text { bypass } \\
\text { losses } \\
\end{array}$ & $\begin{array}{l}\text { Absorbed } \\
\text { Insolation }\end{array}$ & $\begin{array}{l}\text { Emitted by } \\
\text { surface } \\
\text { (Losses) }\end{array}$ & $\begin{array}{l}\text { Air Absorption } \\
\text { (Incoming \& } \\
\text { Outgoing) }\end{array}$ & $\begin{array}{l}\text { Infinite } \\
\text { Recycled } \\
\text { Limit } \\
\end{array}$ & $\begin{array}{l}\text { Energy Lost } \\
\text { to Space } \\
\text { (Concept) }\end{array}$ \\
\hline Incoming Radiation & 342.00 & & & & & & \\
\hline Backscattered by air \& Reflected by clouds & & 53.54 & & & & & \\
\hline Reflected by surface & & 30.00 & & & & & \\
\hline Insolation Absorbed by vapour, dust, Ozone, clouds & & & 73.69 & & 73.69 & 73.69 & \\
\hline Insolation Absorbed by surface & & & 184.77 & & & & \\
\hline Surface Radiation (Fully absorbed by air) & & & & 72.59 & 72.59 & 72.59 & \\
\hline Surface Thermals & & & & 26.40 & 26.40 & 26.40 & \\
\hline Surface Evaporation & & & & 85.79 & 85.79 & 85.79 & \\
\hline \multicolumn{8}{|l|}{ Surface IR Radiation (Atmospheric Window Loss) } \\
\hline Emission by Atmosphere & & & & & & & 172.67 \\
\hline Emission by Clouds & & & & & & & 85.79 \\
\hline Totals & 342.00 & 83.54 & 258.46 & 184.77 & 258.46 & 258.46 & 258.46 \\
\hline
\end{tabular}

Table 13. The Cretaceous Hothouse World.

\begin{tabular}{llll}
\hline Speculative Key Energy Budget Metrics & Power Intensity \% & Power Intensity W/m & Temperature Kelvin \\
\hline Raw Planet Filtered Insolation & $75.57 \%$ & 258.46 & 260 \\
Raw Surface Absorbed Insolation & $54.03 \%$ & 184.77 & 239 \\
Air Absorption (Incoming \& Outgoing) & $75.57 \%$ & 258.46 & -13 \\
\hline
\end{tabular}




\begin{tabular}{|c|c|c|c|c|}
\hline Speculative Key Energy Budget Metrics & Power Intensity \% & Power Intensity $\mathrm{W} / \mathrm{m}^{2}$ & Temperature Kelvin & Temperature Celsius \\
\hline Recycled Atmospheric Energy & $75.57 \%$ & 258.46 & & \\
\hline Enhanced Surface Power Intensity & $205.17 \%$ & 701.68 & 334 & 61 \\
\hline 1. Surface Longwave Radiation (Loss) & $21.22 \%$ & 72.59 & & \\
\hline 2. Surface Thermals (Loss) & $7.72 \%$ & 26.40 & & \\
\hline 3. Surface Evaporation (Loss) & $25.08 \%$ & 85.79 & & \\
\hline Surface Radiant Power Intensity & $151.14 \%$ & 516.91 & 309 & 36 \\
\hline Top of Atmosphere Radiant Exhaust & $75.57 \%$ & 258.46 & 260 & -13 \\
\hline
\end{tabular}

Replacing continental solid land surfaces, with their highly effective thermal emission capability, by a liquid surface of shallow solar-energy absorbing seas, with their low thermal emission capability means that the Earth would capture and transmit more solar energy from the tropics to the poles via the oceanographic currents of a flooded world [10]. Assuming a Cretaceous meteorological distribution of energy flux pro-rata to that of the modern world, then the key energy budget metrics for a $36^{\circ} \mathrm{C}$ world are speculatively recorded in Table 13 .

\section{Conclusions}

There are some fundamental points that come from this analysis of these diagrams of the Earth's energy budget: -

Issue \#1. Internal energy recycling limits the maximum possible temperature rise to an increase of plus $14^{\circ} \mathrm{C}$, assuming total blocking of the longwave atmospheric window and an unchanged Bond albedo.

It is therefore impossible for the Earth to experience a runaway greenhouse gas effect due to changes in the atmospheric thermal radiant opacity if the total mass of the atmosphere does not increase [3].

In order to achieve a putative Cretaceous global average temperature of $36^{\circ} \mathrm{C}$, it is necessary to both reduce the Earth's albedo to 0.244 , and also to apply total blocking of surface-to-space longwave radiation (and/or raise the total mass of the atmosphere).

However the total blocking of the atmospheric window by carbon dioxide gas may not be possible. This is an issue that was studied by Ferenc Miskolczi [11].

Issue \#2. Changes in the value of the Earth's planetary Bond albedo are a valid mechanism by which global warming can occur. Variations in water distribution in the forms of either reflective ice and/or cloud; or absorbing surface water areal variations by either short term sea-ice distribution or long-term geologic ocean distribution (e.g. The Cretaceous Tethys Ocean [12]) is the primary route to change planetary albedo.

This dominance of water either in its reflective role of clouds and ice leading to planetary albedo increase, or in its absorptive form as a transparent surface liquid replacing continental land surfaces or solid polar sea ice, means that there is no albedo role for atmospheric carbon dioxide to change global average temperatures.

Unlike water, carbon dioxide is not a condensing gas in the Earth's atmosphere, and so it has no impact on insolation energy capture via changes in reflective planetary brightness, unlike the droplet stratus clouds and cirrus clouds of ice crystals derived from atmospheric water vapour [13].

Issue \#3. The standard climate model has the following basic features with specific rules applied.

1. The planetary disk geometric intercept rule. - The average solar irradiance is divided by 4 and instantaneously spread over the surface of the globe [7].

2. The albedo bypass rule. - A given percentage of the planetary insolation is bypassed by planetary brightness and is not used within the climate system.

3. The remaining insolation is absorbed by the planet/atmosphere.

4. The planetary atmosphere is leaky. - Low frequency thermal radiation can pass from the planet's surface directly out to space [14].

5. The atmosphere is an energy reservoir.

6. Energy recycling by the atmosphere doubles the quantity of energy in this reservoir. - This is the half in / half out rule of back radiation energy flux partition [7].

7. Rule six limits the maximum possible gain to times two, which is the infinite recycling geometric series limit.

What this all means is that for a planet with a zero albedo surface (that is with $100 \%$ insolation high-energy absorption under a totally clear atmosphere) and a totally opaque atmosphere for exiting surface thermal radiation (that is no surface leaks to space and total $100 \%$ atmospheric thermal radiant blocking) then the absolute limit of the internal energy budget is:

$$
\text { Equation 4: Limit }=>3 * \mathrm{SI} / 4
$$

I.e. Three times the Solar Irradiance flux divided by four.

For planet Earth, with a planetary solar irradiance of $1361.0 \mathrm{~W} / \mathrm{m}^{2}$, the maximum possible planetary energy budget for a hypothetical Bond albedo of zero and totally blocked atmospheric thermal radiant opacity is $1361 * 0.75=1020.75 \mathrm{~W} / \mathrm{m}^{2}[4]$. This flux translates into a maximum possible energy budget thermodynamic temperature of 366.3 Kelvin $\left(93.3^{\circ} \mathrm{C}\right)$ (Table 14).

Table 14. The Hypothetical Zero Albedo, Total Atmospheric Thermal Radiant Opacity, Hothouse Limit

\begin{tabular}{|c|c|c|c|c|}
\hline $\begin{array}{l}\text { Speculative Energy Budget (Total Surface Absorption and } \\
\text { Total Radiant Blocking) }\end{array}$ & $\begin{array}{l}\text { Power } \\
\text { Intensity \% }\end{array}$ & Power Intensity $\mathrm{W} / \mathrm{m}^{2}$ & Temperature Kelvin & $\begin{array}{l}\text { Temperature } \\
\text { Celsius }\end{array}$ \\
\hline Raw Planet Filtered Insolation & $100.0 \%$ & 340.25 & 278 & 5 \\
\hline Raw Surface Absorbed Insolation & $100.0 \%$ & 340.25 & 278 & 5 \\
\hline Air Absorption (Outgoing only) & $100.0 \%$ & 340.25 & & \\
\hline
\end{tabular}




\begin{tabular}{|c|c|c|c|c|}
\hline $\begin{array}{l}\text { Speculative Energy Budget (Total Surface Absorption and } \\
\text { Total Radiant Blocking) }\end{array}$ & $\begin{array}{l}\text { Power } \\
\text { Intensity \% }\end{array}$ & Power Intensity W/m $\mathbf{m}^{2}$ & Temperature Kelvin & $\begin{array}{l}\text { Temperature } \\
\text { Celsius }\end{array}$ \\
\hline Recycled Atmospheric Energy & $100.0 \%$ & 340.25 & & \\
\hline Enhanced Surface Power Intensity & $300.0 \%$ & 1020.75 & 366.3 & 93.3 \\
\hline 1. Surface Longwave Radiation (Loss) & $39.29 \%$ & 133.67 & & \\
\hline 2. Surface Thermals (Loss) & $14.29 \%$ & 48.61 & & \\
\hline 3. Surface Evaporation (Loss) & $46.43 \%$ & 157.97 & & \\
\hline Surface Radiant Power Intensity & $200.00 \%$ & 680.50 & 331 & 58 \\
\hline Top of Atmosphere Radiant Exhaust & $100.0 \%$ & 340.25 & 278 & 5 \\
\hline
\end{tabular}

For the planet Venus, with a solar irradiance of 2601.3 $\mathrm{W} / \mathrm{m}^{2}$, the maximum possible planetary energy budget for a hypothetical Bond albedo of zero and complete atmospheric thermal radiant opacity is $2601.3 * 0.75=1951 \mathrm{~W} / \mathrm{m}^{2}$ [15].

This flux translates into a maximum possible energy budget thermodynamic temperature of 430.7 Kelvin $\left(157.7^{\circ} \mathrm{C}\right)$, but the surface temperature of Venus is 737 Kelvin $\left(464^{\circ} \mathrm{C}\right)$ [15].

From this analysis we can deduce that the standard radiative climate model is compromised and needs to be replaced with a new model [16]. The back-radiation concept cannot explain why Venus has a surface temperature of $464^{\circ} \mathrm{C}$ by atmospheric radiant energy flux recycling. The solar flux captured by the Venusian atmosphere is far too low to produce the observed surface temperature, even if Venus had a solar illuminated Bond albedo of zero and complete atmospheric thermal radiant opacity.

For a resolution of this paradox we propose the adoption of a new climate model, the Dynamic Atmosphere Energy Transport (DAET) model, that is based on meteorological principles and is applicable to all solar illuminated terrestrial type astronomic bodies that possess a dense semi-opaque thermally radiant atmosphere $[3,17,18]$.

\section{References}

[1] OK-FIRST Project Earth's Energy Budget, 1997, Oklahoma Climatological Survey, 100 East Boyd Street, Suite 1210, Norman, OK 73019. Copyright (C) 1996-2005 Oklahoma Climatological Survey. All Rights Reserved.

[2] Kiehl, J. T and Trenberth, K. E., 1997. Earth's Annual Global Mean Energy Budget. Bulletin of the American Meteorological Society, Vol. 78 (2). pp. 197-208.

[3] Wilde, S. P. R. and Mulholland, P. 2020. Return to Earth: A New Mathematical Model of the Earth's Climate, International Journal of Atmospheric and Oceanic Sciences. Vol. 4, No. 2, 2020, pp. 36-53. doi: 10.11648/j.ijaos.20200402.11

[4] Williams, D. R., 2019. Earth Fact Sheet. NASA NSSDCA, Mail Code 690.1, NASA Goddard Space Flight Center, Greenbelt, MD 20771.

[5] Sagan, C. and Chyba, C., 1997. The Early Faint Sun Paradox: Organic Shielding of Ultraviolet-Labile Greenhouse Gases. Science, 276 (5316), pp. 1217-1221.
[6] Jacob, D. J. 1999. Introduction to Atmospheric Chemistry. Princeton University Press.

[7] Mann, M. 2020 One-Layer Energy Balance Model - Meteo 469 From Meteorology to Mitigation: Understanding Global Warming, Department of Meteorology and Atmospheric Science, Penn State College of Earth and Mineral Sciences.

[8] Gale, A. S., 2000. The Cretaceous world. Biotic response to global change: the last 145 Million Years, pp. 4-19.

[9] Golovneva, L. B., 2000. The Maastrichtian (Late Cretaceous) climate in the northern hemisphere. Geological Society, London, Special Publications, 181 (1), pp. 43-54.

[10] Scotese, C. R., 2001. Atlas of Earth History, Volume 1, Paleogeography, PALEOMAP Project, Arlington, Texas, $52 \mathrm{pp}$.

[11] Miskolczi, F. M., 2010. The stable stationary value of the earth's global average atmospheric Planck-weighted greenhouse-gas optical thickness. Energy \& Environment, 21 (4), pp. 243-262.

[12] Walliser, E. O. and Schöne, B. R., 2020. Paleoceanography of the Late Cretaceous northwestern Tethys Ocean: Seasonal upwelling or steady thermocline? PLoS One, 15 (8), p. e0238040.

[13] Leconte, J., Forget, F., Charnay, B., Wordsworth, R. and Pottier, A., 2013. Increased insolation threshold for runaway greenhouse processes on Earth-like planets. Nature, 504 (7479), pp. 268-271.

[14] Simpson, G. C., 1928. Some Studies in Terrestrial Radiation. Royal Meteorological Society (London) Memoir, Vol II. No. 16, pp. 69-95.

[15] Williams, D. R., 2018. Venus Fact Sheet. NASA NSSDCA, Mail Code 690.1, NASA Goddard Space Flight Center, Greenbelt, MD 20771.

[16] Browning, G. L., 2020. The Unique, Well Posed Reduced System for Atmospheric Flows: Robustness In The Presence Of Small Scale Surface Irregularities. Dynamics of Atmospheres and Oceans, p. 101143.

[17] Mulholland, P. and Wilde, S. P. R., 2020. An Inverse Climate Modelling Study of the Planet Venus. International Journal of Atmospheric and Oceanic Sciences. Vol. 4, No. 1, 2020, pp. 20-35. doi: 10.11648/j.ijaos.20200401.13.

[18] Mulholland, P. and Wilde, S. P. R., 2020. An Iterative Mathematical Climate Model of the Atmosphere of Titan, Journal of Water Resources and Ocean Science. Vol. 9, No. 1, 2020, pp. 15-28. doi: 10.11648/j.wros.20200901.13. 